\title{
FRAMEWORK FOR ESTABLISHING FEASIBLE TRANSIT ORIENTED DEVELOPMENT LOCATIONS: A CASE STUDY IN HYDERABAD, INDIA
}

\author{
Prashanth Shekar Lokku' ${ }^{1}$, Chekuri Siva Rama Krishna Prasad ${ }^{2}$ \\ 1,2 Transportation Division, Department of Civil Engineering, National Institute of Technology, \\ Warangal-506004, Telangana, India
}

Received 13 September 2017; accepted 30 January 2018

\begin{abstract}
Transit-Oriented Development (TOD) concept and designs are successfully implemented in developed countries like United States, Australia and United Kingdom. Being motivated by them, developing countries are looking forward to adopt similar concepts. However, these TOD concepts are not directly transferable to developing countries due to factors such as demographic, social, economic, environmental, political and urbanization which play a major role in planning and implementation of new urban development concepts like TOD. Hence, the planning and implementation strategies have to be derived separately at least at national level. In this line, the study proposed a comprehensive planning methodology for TOD implication. Hyderabad, India has taken as case study to adopt proposed methodology at region/city level. As a part of this, a Spatial Multi-Criteria Approach (SMCA) is adopted using Geographic Information System (GIS) at various stages (i.e. population and employment densities, transit and road network, availability of open land and existing land use). In this study, Hyderabad is categorised into 2 parts namely Urban and sub-urban at first stage in the process. After processing the next three level in methodology, Optimum TOD locations were identified and also suggested TOD typology is drawn.
\end{abstract}

Keywords: transit-oriented development, TOD typology, spatial multi criteria analysis.

\section{Introduction}

Urbanisation is taking place very rapidly across the globe. By 2050, two-thirds of world population is going to be urban population as forecasted. In a recent study, United Nations (UN, 2014) revealed that more than half of the world's population is in urban areas. Currently, in India $30 \%$ of people are living in urban area and is expected to increase to $40 \%$ by the year 2039 (UN, 2014). As population increases, private vehicular growth also increases. Hence, such increase in number of private vehicles on urban roads, leads to negative impact on the environment and quality of life deteriorates. To overcome such problems, it is necessary to reduce the usage of private vehicles and build a liveable condition within the city, which may be possible with TOD.

TOD has several dimensions to explore. Over the decades the design methods and implementation of TOD has been changing

\footnotetext{
${ }^{1}$ Corresponding author: prashanth.lokku@student.nitw.ac.in
} 
to meet the sustainability measures. Initially TOD technique was used to reduce the private vehicle usage to improve the quality of environment and in some cases to develop the economically backward areas. Hence, the transportation planners and engineers worked to allocate maximum number of people to stay and work within a walkable distance from transit station, which affects their travel characteristics such as travel cost, trip length, safety, comfort etc. In this context, TOD concept is formed based on Density, Diversity and Design.

In India most of the cities are unplanned and it results in disordered travel patterns of people. Therefore, it is difficult to understand the urban development pattern and its structural form in developing countries. (Cervero et al., 2002) have mentioned about 3D laws for TOD - Density, Diversity and Design. In Indian context the first two laws i.e. Density and Diversity are present. However, these Density and Diversity are not meeting the necessity of the present demand. Design elements are completely lacking in developing countries like India. In such conditions, there is a need of best suitable and optimal plans for developing countries to make the city a sustainable city.

In other words, TOD is an integration of land use and urban transportation system, which is the biggest challenge in developing countries. Hence, to address such challenges there is a need to develop methodology at region/city level planning (macro level) to address various transport and land use related issues. Introducing TOD concept along the transit stations may not be possible. Further, to develop a sustainable city, it is necessary to understand the urbanization and growth of urban sprawl over the years in developing countries. Metropolitan cities in India are historical places and pattern of urban sprawl more or less followed same trend. The average population density is about 20,000 persons per square kilometre in metro cities in India. It is really a big number when compared with developed countries as shown in Fig. 1.

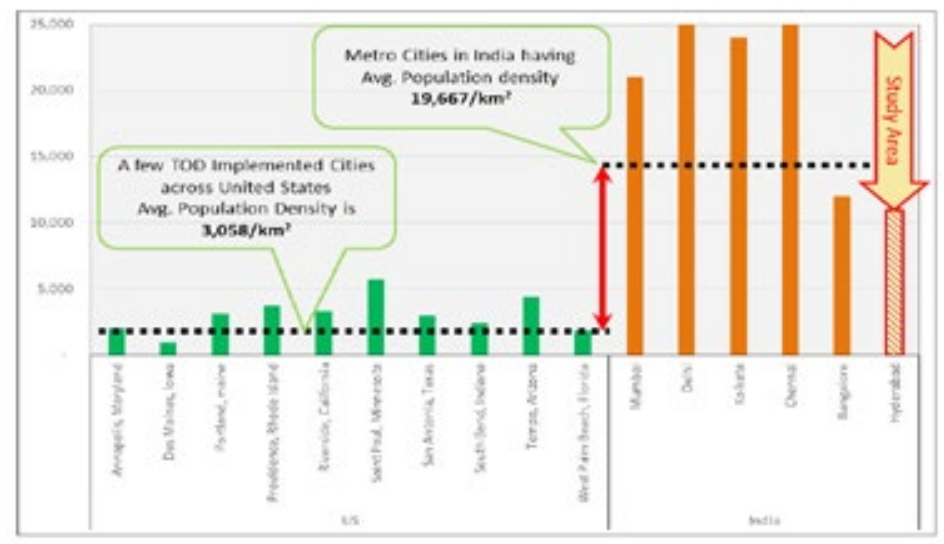

Fig.1.

Comparison between TOD Implemented Cities in United States and Metro Cities in India 
So it can be said that in India, cities are like development oriented transit systems. Hence, it is necessary for Indian cities to explore at city level to make sustainable lives for future generations through emphasis of TOD concept. In this context, the objective of the present study is to understand the ground realities and to propose a region/city level planning methodology for implication of TOD.

\section{Literature Review}

Transit Oriented Development (TOD) is a well-known concept, however research studies on this topic has seen resurgence in recent years. A research study by Calthorpe's (1993) “The Next American Metropolis" is the major work responsible for reintroducing these concepts to planning and development professions. In another study, (Hasibuana et.al., 2014) has explained about historical changes in transport segment in United States. This study has been categorised into three major stages. Stage 1 is known to be Development Oriented Transportation (DOT), the era in between the years 1850 to 1930 . During the early twentieth century, DOT more suitably described many towns and cities than TOD, as private developers built transit services to serve their development rather than vice versa. The Auto Oriented Development (AOD), took place during 1930 to 1960 after world war II in Stage 2. At this stage transit usage decreased and people depended largely on private vehicles, as a result of that congestion happened. In order to release this congestion, the Transit systems were planned in Stage 3. Stage 3 is known as TOD era since 1960 s, many researchers explained about integration of land with transportation facility, causing sustainable lives. It has many advantages such as reduction in travel expenses, improvement in quality of life via less pollution emission, healthy environment for walking and non-motorized transport (NMT) facilities nearby station.

TOD plays a major role to make financially viable or induce the people towards public transportation. Researchers stated that TOD is the concept of creation of pleasant areas, more liveable communities, encouraging of NMT to make a quality living environment. TOD offers to live, work, shop and relax within walkable distance of $500 \mathrm{~m}$ around the transit station. To achieve these advantages of TOD, land-use and transit integration is considered as one of the important measures to build TOD.

Design of TOD is found to be most relevant option for urban planners and transportation engineers to make city sustainable. However, land-use and integration of transit system is the integral part of sustainable development. Researchers have discussed the advantages, challenges and implementation measures in their research about integration of land use and transit systems (Cervero et al., 2002; Bernick et al., 1997; Li et al., 2009).

In recent years, few researchers have revealed the advantages of TOD (Galelo et al., 2014, Lin and Gau, 2006; Nahlik and Chester, 2014). Developing countries have started exploring the TOD concepts and suitability of TOD from the existing studies of developed countries. Researchers have revealed the suitability of existing developed countries TOD models to Chinese cities, where it cannot be simply transferred and ultimately developed TOD designs and procedures appropriate for China (Li et al., 2009). (Zhiqiang et al., 2008) listed the requirements for successful implementation of TOD in china based on 
past experience. Among them few are ensure the economic conditions to support TOD, preparation of comprehensive plan prior to the development, availability of land for development, should have huge capacity of public transportation system and integrated planning among the different transportation systems.

(Zou et al., 2014) in view of cities in China, proposed planning principles of TOD in the aspects of rational size of TOD, land use intensity, land use structure and road system. Also he discussed about concept, back ground and history of TOD, classification and function of different TOD communities (Zou et al., 2014). (Zhao, 2008), presented the planning of TOD for sustainable Chinese cities. He analysed at macro, meso and micro level through qualitative and quantitative description aspects of TOD. (Fard, 2013), research provided a quantitative measure of TOD levels based on existing situations, facilitate prioritization of development interventions. (Serge and Gerald, 2017) mentioned about transforming the urban space through TOD. The main focus of the study is to derive the planning and strategies of TOD at city level, network level and local level.

In this view, in India few research studies have been carried in recent years with respect to design of TOD. To get maximum benefit from TOD, UTTIPEC Report (2012) set two main objectives such as "reduce private vehicle dependency and induce public transport use through design, policy and enforcement measures". The second objective is to "provide Public Transit access to maximum number of people through densification and enhanced connectivity". However, these studies did not consider the ground realities to propose a region level planning methodology of TOD. It is important to consider the road network to implement TOD, as developing countries have limited transit system corridors. The outcome of this study would be the optimum TOD locations means identification of minimum number of TODs for implication and to get maximum benefits with respect to sustainable measure.

\section{Methodology}

Working methodology for planning of TOD for developing countries like India, it is necessary to understand all the elements which effect the implementation stage. To plan any concept related to urban planning, one has to understand number of challenges such as land use, traffic and transportation facilities, social issues, environment impacts, economic consideration, urban morphology and political pressures. This research work aims at segregation of most impacted challenges into different categories and analysing them by Spatial Multi Criteria Analysis (SMCA) by using Geographic Information System (GIS) to bring out best optimal TOD locations. Different types of TOD can be drawn based on number of criteria (viz., population and employment) and number of categories (viz., High, Medium, Low) in each criteria.

In this study, SMCA is adopted and performed at four stages one after the other as shown in Fig. 2. In Stage 1, Urban Morphology is considered to delineate the study area into categories based on population and employment density such as Core Urban (U1), Urban (U2), Suburban (U3), Core Urban TOD, Urban TOD and Suburban TOD. Initially the study area is divided into smaller zones and 
for each zone, population and employment densities are calculated as given in Eq. (1) and Eq. (2):

$$
\text { Density }_{\text {pop }}=\frac{\text { Population of zone } i}{\text { Area of Zone } i}
$$

$$
\text { Density }_{\text {emp }}=\frac{\text { Employment of zone } i}{\text { Area of Zone } i}
$$

Stage 2 is crucial to select most appropriate TOD locations. In this stage, Transportation Network (Transit and Road Network) of complete city is considered. The development proposals are based on the transportation facility available like Expressways (T1), Mass Rapid Transit Systems-MRTS (T2), Light Rail Transit (T3), Mono Rail (T4), etc. Before performing this analysis, rules are made to choose the eligible Transportation network. To select TOD locations, Transit network is completely considered and Road network with speed more than $25 \mathrm{~km} / \mathrm{h}$ within urban area is considered. In addition to this, for suburban area grid analysis is performed and TOD locations are selected based on the existing settlements and available road network. Further, Density and Design parameters can be organised more appropriately at this level.

Stage 3, deals with built up environment along the finalised TODs in stage 2 . This stage is crucial for development of proposals. Analysis is carried out for urban area only, as densities are low in suburban area. TOD area is considered within $500 \mathrm{~m}$ from transit station. Percentage of land availability is calculated as shown in equation (3). Based on available land, development proposals may be categorised into High (B1), Moderate (B2) and Low (B3).

$\%$ of Land Available $=\frac{\text { open Land Area with in } T O D_{i}}{\text { TOD }_{i} \text { Area }}$

In stage 4, percentage of land use is calculated category wise at each selected location for urban TOD. Based on predominant type of land use, typology is proposed. Diversity measures such as Residential (L1), Commercial (L2), Institutional (L3) and Mixed (L4) are considered.

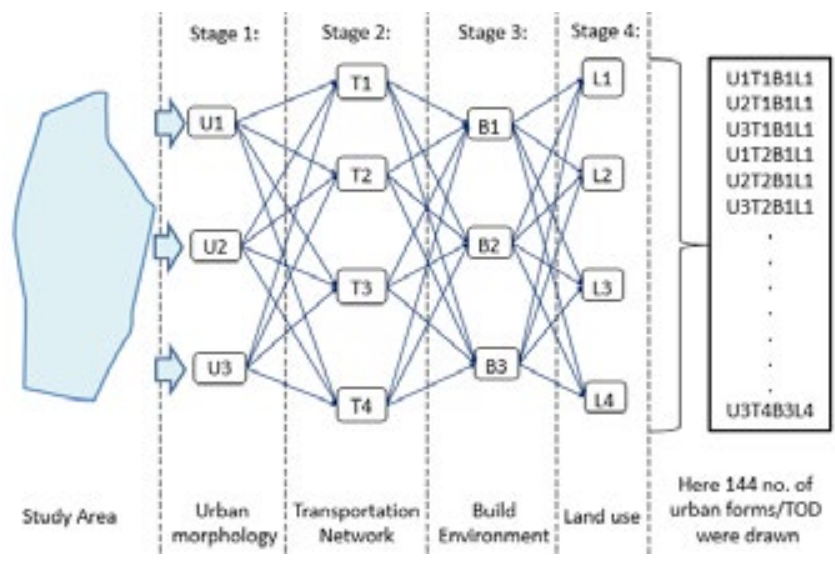

Fig. 2.

Framework Based on SMCA 


\section{Study Area}

To carry out this research work, Hyderabad Metropolitan Area (HMA) is considered as a case study. HMA ranks $6^{\text {th }}$ and $3^{\text {rd }}$ in population and area respectively, among the metropolitan cities in India. HMA population is about 10 million as of now (2016) and is estimated to be 19 million by the year 2041 (CTSHMA, 2013). Also, HMA has an area of 7,200 Sq Km. Moreover, the registered vehicles in HMA are 2.5 lakhs (year 2011) with a growth rate of $11 \%$ per year and road length of $5500 \mathrm{~km}$. Initially, the study area is commissioned by Municipal Corporation of Hyderabad $(\mathrm{MCH})$, as growth occurred and urban sprawl increased tremendously, then it is converted to Greater Municipal Corporation of Hyderabad (GHMC). Further in 2008, with extended area Hyderabad Municipal Development Authority (HMDA) was formed. However, with the increase in travel demand in urban area, Hyderabad city is facing several problems such as traffic congestion, quality of environment and access to public transportation. To mitigate these problems, authorities (viz., GHMC, HMDA) have planned MRTS with a length of $72 \mathrm{~km}$. In addition to this, HMA has other transit system as Multi-Modal Transport System (MMTS) which is present since 2003, with a length of $44 \mathrm{~km}$ and 36 stations. However, it runs on existing rail track only, not as per public travel demand.

\section{Analysis and Results}

As discussed in methodology, SMCA is adopted in this study. HMA is delineated into 695 Traffic Analysis Zones (Source: Transportation cell, HMDA), population and employment is allocated for these zones. In Stage 1, Urban Morphology is studied. Population and employment densities are calculated as discussed in methodology and plotted on map as shown in Fig. 3. From Fig. 3 , notable density can be observed within core area that is GHMC. Within the core area, maximum and average population densities are about 700 and 260 persons per hectare respectively. Outside GHMC, average population density is 8 persons per hectare and represented as rural area and it is the similar case even in employment. Further based on density patterns, the study area is divided into two categories, namely urban and suburban.

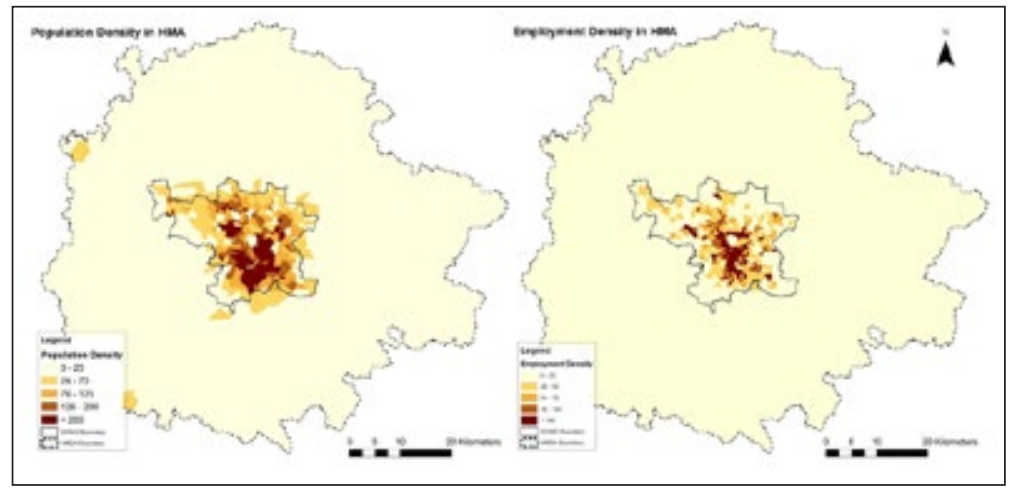

Fig. 3.

Population and Employment Density 
Transportation Network is considered in Further, a total of 72 MRTS stations and 36 stage 2. In this Transit Network (MRTS, MMTS are considered in the study area as MMTS) and Road Network are considered. shown in Fig. 4.

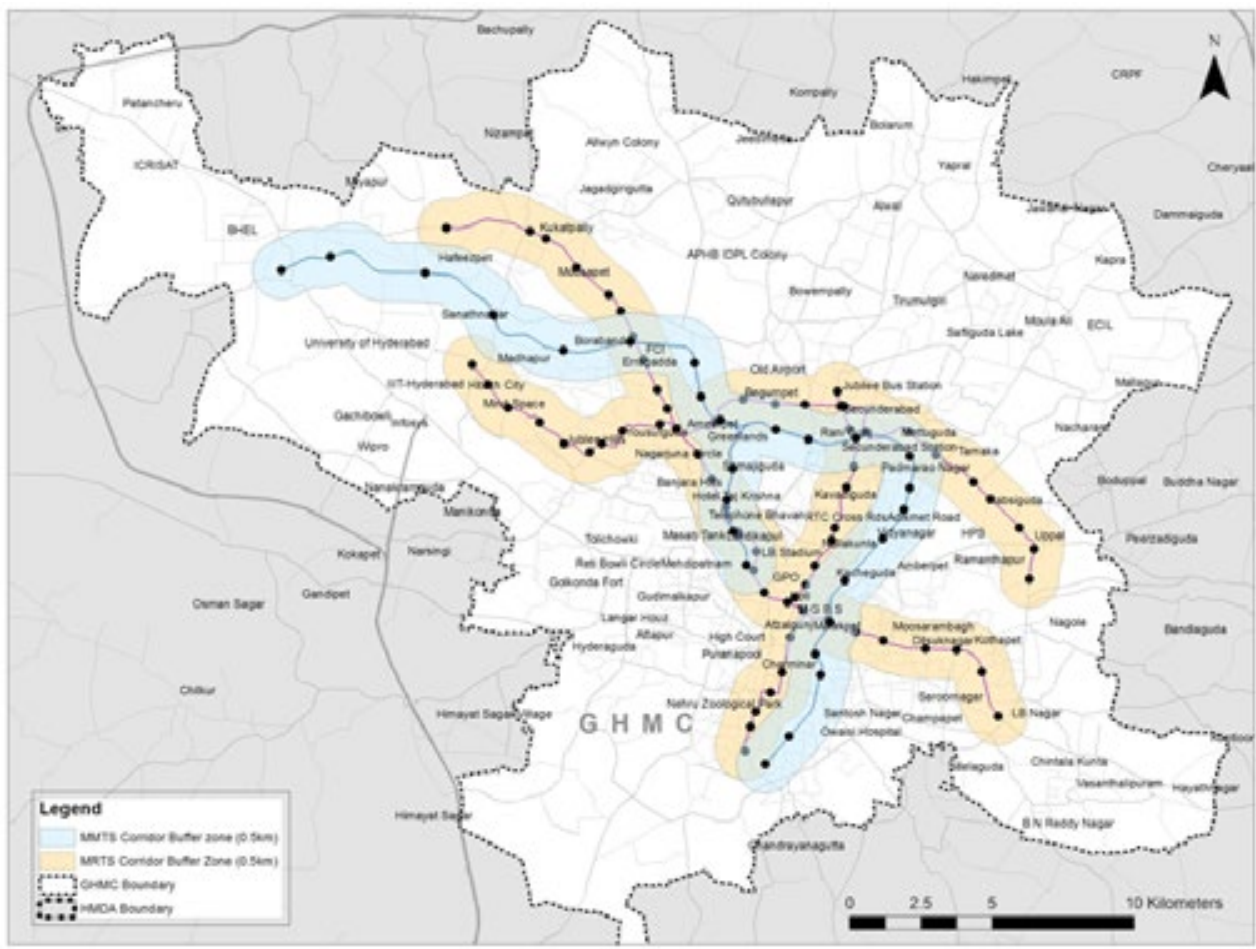

Fig. 4.

Transit Networks in HMA with $500 \mathrm{~m}$ Buffer

Influence area for both the transit systems considered is $500 \mathrm{~m}$ on either side of corridor, which is about $3 \%$ of HMA. In order to select the best optimal TOD locations, following rules are framed.

Rule 1: Integrated station locations of MMTS, MRTS and intercity terminals are considered with high priority.

Rule 2: Interchange transit stations, end point of each transit corridor are recommended for TOD.

Rule 3: Road Network with speed more than $25 \mathrm{~km} / \mathrm{h}$, crowded local economic activity areas and residential pockets are taken into account for TOD selection.

As per aforementioned TOD rules, 34 urban TOD locations are selected out of 108 transit stations as shown in Fig. 5. 


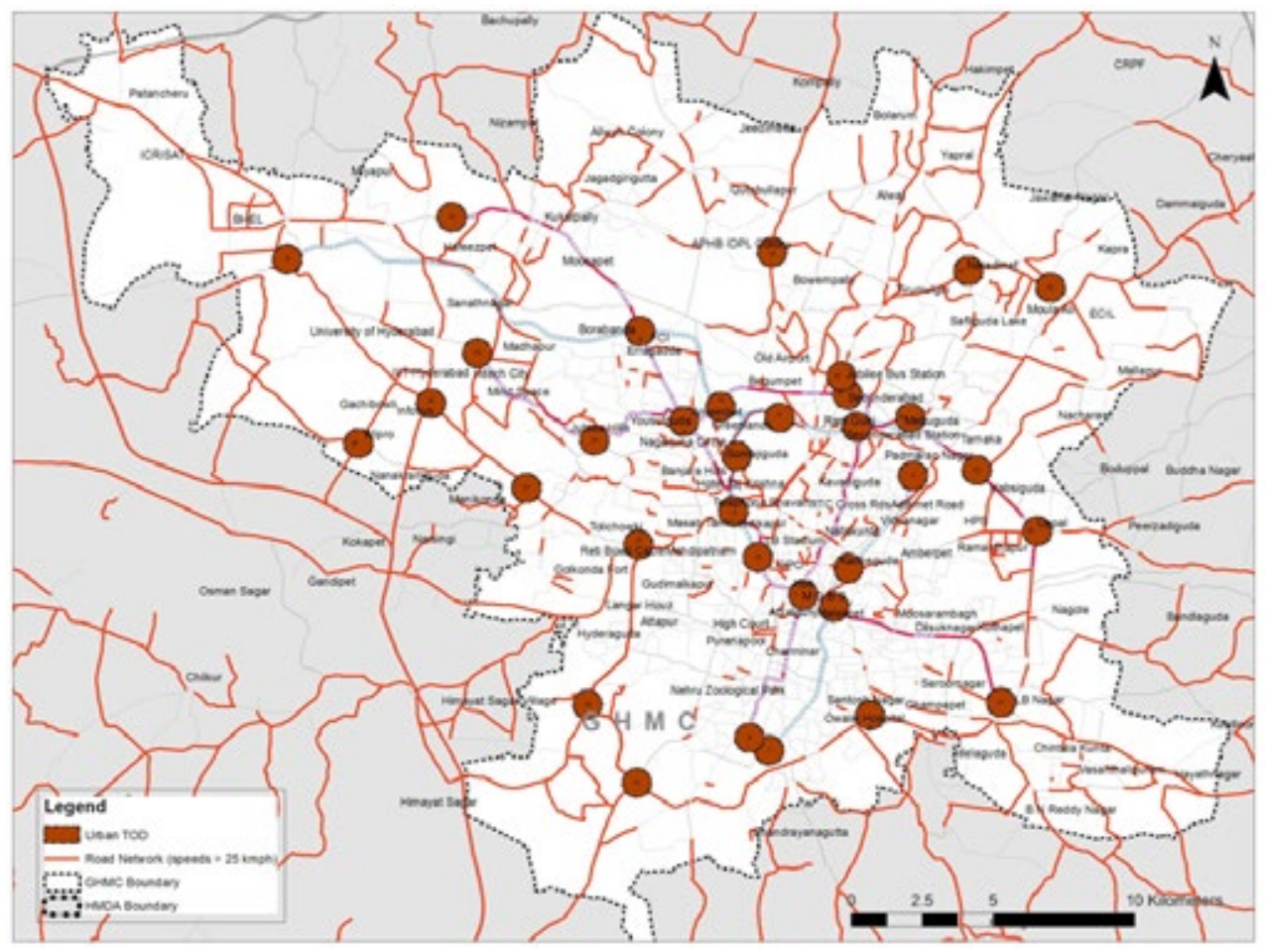

Fig. 5.

Urban TOD Locations

For Suburban area, hierarchical Road Network is considered based on speed and number of lanes. Further rules are drawn to select TOD locations.

Rule 1: Grid analysis is carried out to have uniform urban sprawl across the study area. A Grid size of $4 \mathrm{~km} \mathrm{X} 4 \mathrm{~km}$ is considered for this study area and the maximum distance between each TOD considered is about $8 \mathrm{~km}$.

Rule 2: Population and employment settlements are considered.
Rule 3: National Highways, State Highways with vehicle speed more than $40 \mathrm{~km} / \mathrm{h}$ are considered.

As these TODs are identified in rural/ sub urban areas, Non-Motorised Transport (NMT) is considered besides acceptable walking distance (i.e. $500 \mathrm{~m}$ ). By applying the above rules to the study area, 34 TODs are obtained as shown in Fig. 6. 


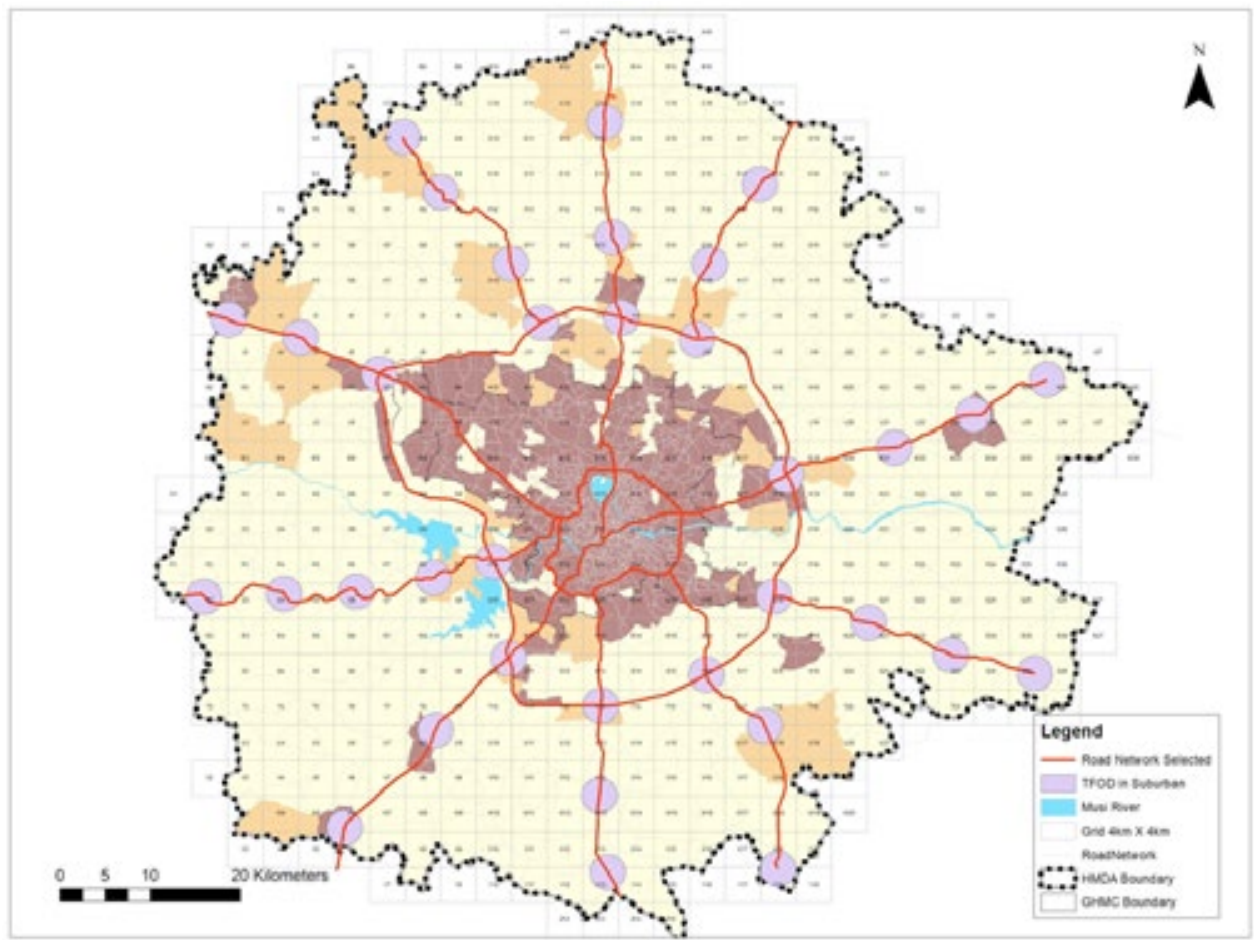

Fig. 6.

Suburban TOD Locations

In Stage 3, the urban TODs obtained from stage 2 are reviewed based on the built up area. Built up area is identified using Google Earth and imported to ArcGIS for analysing the best possibility of TOD locations as shown in Fig. 7. Based on the percentage of land availability (irrespective of its category),
TODs are categorised into three (viz., High, Medium, Low). In this study area out of 34 TODs, 7 TODs have more than $40 \%$ land availability, 10 TODs with $20 \%-40 \%$ and 17 TODs have less than 20\% land availability. Based on this, development policies can be drawn to get best outcomes. 


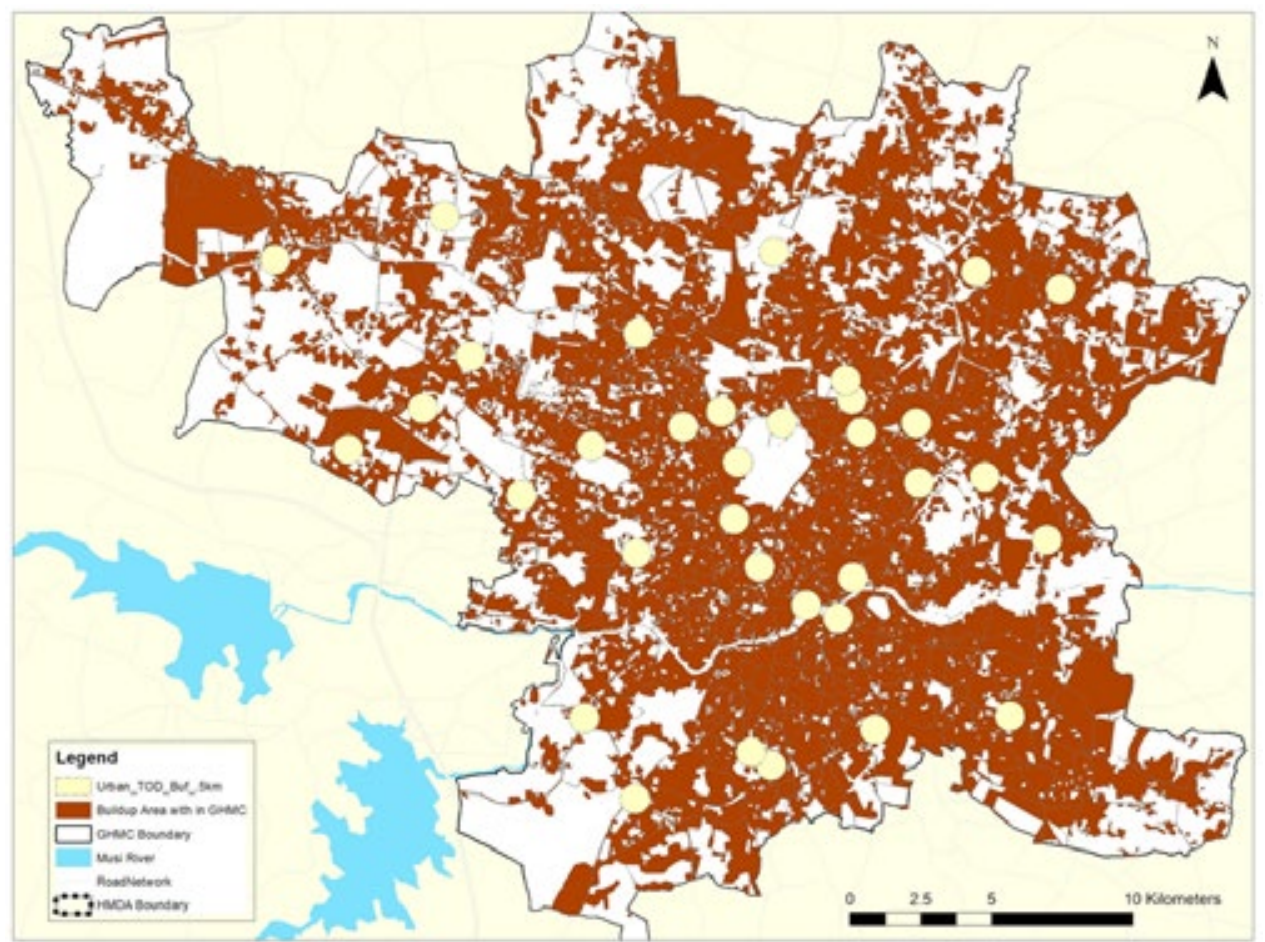

Fig. 7.

Built-up Area within GHMC

In Stage 4, Urban TODs are analysed based on existing land use details (collected from HMDA) within $500 \mathrm{~m}$ radius. Based on the four predominant land use types (residential, commercial, institutional and mixed) the TOD is categorised so. For example, Neredmet area is covered by $60 \%$ residential land use and is suggested for residential TOD. Aramgarh has equal share of residential and commercial land use of $19 \%$ and is suggested for mixed TOD. Further this analysis is helpful for better maintenance of TOD. Table 1 , final results of this stage is presented.

Urban TOD type proposed for the study area is given in Table 1. It is prioritised based on Speed of the transportation System. In this case MRTS speed is more followed by MMTS and Road network. Also showed the TOD falls on which transportation system.

\section{Summary}

A total of 34 and 35 numbers of Urban and Suburban TODs are obtained respectively. Table 1 is given the list and their specific ground characteristics to categorise them to have optimal design plans. For any successive TOD, planning before implementation is the key. In case of suburban TOD (35 No's), a comprehensively one single plan can be executed because of the nature of locations are almost same expect one or two as shown in the Fig. 6. 
Table 1

Stage Wise Results of Urban TODs

\begin{tabular}{|c|c|c|c|c|c|}
\hline $\begin{array}{l}\text { Urban } \\
\text { TOD No }\end{array}$ & Location Name & $\begin{array}{l}\text { Stage 1: } \\
\text { Urban } \\
\text { Morphology }\end{array}$ & $\begin{array}{l}\text { Stage 2: } \\
\text { Transportation } \\
\text { System }\end{array}$ & $\begin{array}{l}\text { Stage 3: } \\
\text { Land Availability }\end{array}$ & $\begin{array}{l}\text { Stage4: } \\
\text { TOD Typology }\end{array}$ \\
\hline 1 & Falaknuma MMTS & Urban & MMTS & Between $20 \%$ - $40 \%$ & Residential \\
\hline 2 & Falaknuma Metro & Urban & MRTS & Less than $20 \%$ & Residential \\
\hline 3 & MGBS & Urban & MRTS & Between $20 \%$ - $40 \%$ & Mixed \\
\hline 4 & Arts College & Urban & MMTS & Less than $20 \%$ & Institutional \\
\hline 5 & Kachiguda & Urban & MMTS & Less than $20 \%$ & Mixed \\
\hline 6 & Sanjeevaiah Park & Urban & MMTS & Greater Than $40 \%$ & Mixed \\
\hline 7 & Necklace Road & Urban & MMTS & Greater Than $40 \%$ & Commercial \\
\hline 8 & Lingampalli & Urban & MMTS & Between $20 \%$ - $40 \%$ & Mixed \\
\hline 9 & Bharatnagar & Urban & MRTS +MMTS & Between $20 \%$ - $40 \%$ & Residential \\
\hline 10 & Begumpet & Urban & MRTS +MMTS & Less than $20 \%$ & Commercial \\
\hline 11 & Secunderabad & Urban & MRTS +MMTS & Less than $20 \%$ & Mixed \\
\hline 12 & Nampally & Urban & MRTS +MMTS & Less than $20 \%$ & Mixed \\
\hline 13 & Lakdikapul & Urban & MRTS +MMTS & Less than $20 \%$ & Commercial \\
\hline 14 & Malakpet & Urban & MRTS +MMTS & Less than $20 \%$ & Mixed \\
\hline 15 & Miyapur & Urban & MRTS & Greater Than $40 \%$ & Residential \\
\hline 16 & Ameerpet & Urban & MRTS & Less than $20 \%$ & Institutional \\
\hline 17 & Parade Ground & Urban & MRTS & Less than $20 \%$ & Mixed \\
\hline 18 & Jubilee Bus Station & Urban & MRTS & Less than $20 \%$ & Mixed \\
\hline 19 & Mettuguda & Urban & MRTS & Less than $20 \%$ & Residential \\
\hline 20 & Uppal & Urban & MRTS & Between $20 \%$ - $40 \%$ & Mixed \\
\hline 21 & LB Nagar & Urban & MRTS & Less than $20 \%$ & Mixed \\
\hline 22 & Habsiguda & Urban & MRTS & Between $20 \%$ - $40 \%$ & Mixed \\
\hline 23 & Shilparamam & Urban & MRTS & Greater Than $40 \%$ & Commercial \\
\hline 24 & Jubilee Check post & Urban & MRTS & Between $20 \%$ - $40 \%$ & Residential \\
\hline 25 & Rethibowli & Urban & Road Network & Less than $20 \%$ & Mixed \\
\hline 26 & Rajendernagar & Urban & Road Network & Between $20 \%-40 \%$ & Residential \\
\hline 27 & ShaikpetDarga & Urban & Road Network & Greater Than $40 \%$ & Mixed \\
\hline 28 & Gachibowli & Urban & Road Network & Greater Than $40 \%$ & Commercial \\
\hline 29 & $\begin{array}{l}\text { Gachibowli-Wipro } \\
\text { Junction }\end{array}$ & Urban & Road Network & Between $20 \%$ - $40 \%$ & Commercial \\
\hline 30 & OwasiBusstop & Urban & Road Network & Less than $20 \%$ & Residential \\
\hline 31 & Aramgarh & Urban & Road Network & Between $20 \%-40 \%$ & Mixed \\
\hline 32 & ECIL & Urban & Road Network & Less than $20 \%$ & Mixed \\
\hline 33 & Neredmet & Urban & Road Network & Less than $20 \%$ & Residential \\
\hline 34 & $\begin{array}{l}\text { Dairyform Road on } \\
\text { Old NH7 }\end{array}$ & Urban & Road Network & Greater Than $40 \%$ & Mixed \\
\hline
\end{tabular}

It can be observed that total 23 type of TODs are obtained from the urban area. Based on each type (TOD typology), design will be proposed. For example, from Table 2, Necklace road (Urban TOD No. 7) location has noted typology as U1-T1-B1-L2. Which represents,
U1 Urban TOD (indicates to plan for Higher density), T1-road based (indicates to plan according to its capacity), B1- land availability (indicates highly available) and L2-type of land (indicates to propose Commercial). In same manner total 23 scenarios are tired. 
Table 2

Proposed Typology based on SMCA

\begin{tabular}{|c|c|c|c|c|c|c|}
\hline Urban & Location & Stage 1: & Stage 2: & Stage 3: & Stage4: & TOD \\
\hline TOD No & Name & Urban & $\begin{array}{l}\text { Transportation } \\
\text { System }\end{array}$ & $\begin{array}{l}\text { Land } \\
\text { Availability }\end{array}$ & $\begin{array}{l}\text { Land } \\
\text { use } \\
\end{array}$ & Typology \\
\hline 7 & Necklace Road & U1 & $\mathrm{T} 1$ & B1 & $\mathrm{L} 2$ & U1-T1-B1-L2 \\
\hline 6 & Sanjeevaiah Park & U1 & $\mathrm{T} 1$ & $\mathrm{~B} 1$ & $\mathrm{~L} 4$ & U1-T1-B1-L4 \\
\hline 1 & Falaknuma MMTS & U1 & $\mathrm{T} 1$ & $\mathrm{~B} 2$ & L1 & U1-T1-B2-L1 \\
\hline 8 & Lingampalli & U1 & $\mathrm{T} 1$ & $\mathrm{~B} 2$ & $\mathrm{~L} 4$ & U1-T1-B2-L4 \\
\hline 4 & Arts College & U1 & $\mathrm{T} 1$ & B3 & L3 & U1-T1-B3-L3 \\
\hline 5 & Kachiguda & U1 & $\mathrm{T} 1$ & B3 & L4 & U1-T1-B3-L4 \\
\hline 15 & Miyapur & U1 & $\mathrm{T} 2$ & $\mathrm{~B} 1$ & L1 & U1-T2-B1-L1 \\
\hline 23 & Shilparamam & U1 & $\mathrm{T} 2$ & $\mathrm{~B} 1$ & $\mathrm{~L} 2$ & U1-T2-B1-L2 \\
\hline 24 & Jubilee Check post & U1 & $\mathrm{T} 2$ & $\mathrm{~B} 2$ & L1 & U1-T2-B2-L1 \\
\hline 3 & MGBS & U1 & $\mathrm{T} 2$ & $\mathrm{~B} 2$ & $\mathrm{~L} 4$ & U1-T2-B2-L4 \\
\hline 20 & Uppal & U1 & $\mathrm{T} 2$ & $\mathrm{~B} 2$ & $\mathrm{~L} 4$ & U1-T2-B2-L4 \\
\hline 22 & Habsiguda & U1 & $\mathrm{T} 2$ & $\mathrm{~B} 2$ & $\mathrm{~L} 4$ & U1-T2-B2-L4 \\
\hline 2 & Falaknuma Metro & U1 & $\mathrm{T} 2$ & B3 & $\mathrm{L} 1$ & U1-T2-B3-L1 \\
\hline 19 & Mettuguda & U1 & $\mathrm{T} 2$ & B3 & $\mathrm{L} 1$ & U1-T2-B3-L1 \\
\hline 16 & Ameerpet & U1 & $\mathrm{T} 2$ & B3 & L3 & U1-T2-B3-L3 \\
\hline 17 & Parade Ground & $\mathrm{U} 1$ & $\mathrm{~T} 2$ & B3 & L4 & U1-T2-B3-L4 \\
\hline 18 & Jubilee Bus Station & $\mathrm{U} 1$ & $\mathrm{~T} 2$ & B3 & L4 & U1-T2-B3-L4 \\
\hline 21 & LB Nagar & U1 & $\mathrm{T} 2$ & B3 & L4 & U1-T2-B3-L4 \\
\hline 9 & Bharatnagar & U1 & T3 & $\mathrm{B} 2$ & L1 & U1-T3-B2-L1 \\
\hline 10 & Begumpet & U1 & T3 & B3 & L2 & U1-T3-B3-L2 \\
\hline 13 & Lakdikapul & U1 & T3 & B3 & $\mathrm{L} 2$ & U1-T3-B3-L2 \\
\hline 11 & Secunderabad & U1 & T3 & B3 & L4 & U1-T3-B3-L4 \\
\hline 12 & Nampally & U1 & T3 & B3 & L4 & U1-T3-B3-L4 \\
\hline 14 & Malakpet & U1 & T3 & B3 & L4 & U1-T3-B3-L4 \\
\hline 28 & Gachibowli & U1 & $\mathrm{T} 4$ & $\mathrm{~B} 1$ & L2 & U1-T4-B1-L2 \\
\hline 27 & ShaikpetDarga & U1 & $\mathrm{T} 4$ & $\mathrm{~B} 1$ & L4 & U1-T4-B1-L4 \\
\hline 34 & $\begin{array}{l}\text { Dairyform Road on } \\
\text { Old NH7 }\end{array}$ & U1 & $\mathrm{T} 4$ & $\mathrm{~B} 1$ & L4 & U1-T4-B1-L4 \\
\hline 26 & Rajendernagar & U1 & $\mathrm{T} 4$ & $\mathrm{~B} 2$ & L1 & U1-T4-B2-L1 \\
\hline 29 & $\begin{array}{l}\text { Gachibowli-Wipro } \\
\text { Junction }\end{array}$ & U1 & $\mathrm{T} 4$ & $\mathrm{~B} 2$ & L2 & U1-T4-B2-L2 \\
\hline 31 & Aramgarh & U1 & $\mathrm{T} 4$ & $\mathrm{~B} 2$ & L4 & U1-T4-B2-L4 \\
\hline 30 & OwasiBusstop & U1 & $\mathrm{T} 4$ & B3 & L1 & U1-T4-B3-L1 \\
\hline 33 & Neredmet & U1 & $\mathrm{T} 4$ & B3 & L1 & U1-T4-B3-L1 \\
\hline 25 & Rethibowli & $\mathrm{U} 1$ & $\mathrm{~T} 4$ & B3 & L4 & U1-T4-B3-L4 \\
\hline 32 & ECIL & U1 & $\mathrm{T} 4$ & B3 & L4 & U1-T4-B3-L4 \\
\hline
\end{tabular}

\section{Conclusions}

The proposed study frame work is considered at macro level planning of optimum TOD location and its typology. This study will help to reorient urban formation to achieve sustainability. From core urban area, out of 108 transit stations, 24 are selected through developed framework. Based on road network facility, 10 and 35 TODs are obtained in urban and suburban areas respectively. Comprehensively a total of 69 new TODs were obtained for study area, which are located spatially covering all parts 
of HMA. The dynamics of demand models will change and travel pattern spreads all across the study area. Hence, the busiest corridors may get decongested and leading towards sustainability. From the summary of this study, it is noticed that 23 types of TOD were identified. TOD typology will play a very crucial role at implementation and maintenance phases.

\section{References}

Bernick, M.; Cervero, R. 1997. The Transit Village in the $21^{\text {st }}$ Century, McGraw-Hill, New York. USA.

Calthorpe, P. 1993. The Next American Metropolis: Ecology, Community and the American Dream, New York, Princeton Architectural Press.

Cervero, R.; Ferrell, C.; Murphy, S. 2002. TCRP Research result digest: Transit oriented development and Joint development in the United States: A literature Review, Transportation Research Board of the National Academics 52: 1-144.

CTSHMA Report. 2013. Long Term Strategy for the Transport Sector of HMA-2041. Hyderabad Metropolitan Development Authority. Available from internet: <http:// ctshma2011.finnaclle.com/downloads.php>.

Fard, P. 2013. Measuring TOD: Implementing a GIS-based analytical tool for measuring existing TOD levels, Master's thesis, University of Twente, Netherlands.

Galelo, A.; Ribeiro, A.; Martinez, L.M. 2014. Measuring and Evaluating the Impacts of TOD Measures-Searching for Evidence of TOD Characteristics in Azambuja Train Line, Procedia-Social and Behavioral Sciences 111(5): 899-908.
Li, C.N.; Lai, T.Y. 2009. Why should cities change from DOT to TOD, Proceedings of Institute of Civil EngineersTransport 162(2): 71-79.

Lin, J.J.; Gau, C.C. 2006. A TOD planning model to review the regulation of allowable development densities around subway stations, Journal of Land Use Policy 23(3): 353-360.

Nahlik, M.J.; Chester, M.V. 2014. Transit-oriented smart growth can reduce lifecycle environmental impacts and household costs in Los Angeles, Transport policy 35: 21-30.

Serge, S.; Gerald, O. 2017. Transforming the urban space through TOD: The 3V approach. World Bank Group. Washington DC. USA.

UN. 2014. United Nations Department of Economic and Social Affairs population Division, POPFACTS, No. 2014/3. Available from internet: <http://www.un.org >.

UTTIPEC Report. 2012. Transit Oriented Development: Policy-Norms-Guidelines. Delhi Development Authority. New Delhi. India.

Zhao, J. 2008. Study on planning methodology of TOD for Chinese cities. Master's thesis. Tsinghua University, Beijing, China.

Zhiqiang, L.; Feng, C.; McGinnis, R.G. 2008. TransitOriented-Development (TOD) Suitable for China. In Transportation and Development Innovative Best Practices 2008, 271-276.

Zou, M.; Lin, X.; Mao, C.; Zhang, K.; Li, M. 2014. Review on the theory and planning principle of TransitOriented Development. In CICTP 2014: Safe, Smart, and Sustainable Multimodal Transportation Systems, 3532-3547.

Hasibuana, H.S.; Soemardia, T.P.; Koestoerb, R.; Moersidik, S. 2014. The Role of Transit Oriented Development in constructing urban environment sustainability, the case of Jabodetabek, Indonesia, Procedia Environmental Sciences 20: 622- 631. 